\title{
Development of Causal Relationship Model of Learning Behavior via Internet of Lower Secondary Students in Bangkok Metropolis
}

\author{
Assoc. Prof. Punnee Leekitchwatana, Ed.D. \\ Faculty of Industrial Education, \\ King Mongkut's Institute of Technology Ladkrabang, Bangkok, Thailand, 10520 \\ klpunnee@kmitl.ac.th
}

Doi: $10.5901 / m j s s .2013 . v 4 n 4 p 39$

Abstract

At present, internet is global information level that plays a very important role increasingly. It's useful more or less depends on internet user behavior. Lower secondary school students are a group of people who close to and have most opportunity to use internet. Therefore, to study and understand their behaviors and causes of learning behavior via internet of lower secondary school students will be useful together with explain the cause of their behaviors. For that reason, this research has objective to study behavior and develop the causal relationship model of learning behavior via internet of lower secondary school students by selecting the causal relationship model of structural equation with latent variables. The independent variables included both of external and internal of student together. Data collection was conducted with 1,500 lower secondary school students in Bangkok Metropolis in academic year of 2011. The used questionnaire was 6 rating scales that composed of 128 items covering 20 observed variables. It had construct validity and construct reliability of 7 latent variables at good criteria. Statistics analysis was mean, standard deviation and SEM by LISREL program. The results illustrated as the followings.

1. Students had learning behavior via internet as whole at moderate level in every group both whole and sub-group classified according to sex and educational area into 5 sub-groups of male group, female group, Bangkok Metropolis area 1, area 2 and area 3.

2. The developed causal relationship had validity at good criteria for every model. The whole causal variables were able to predict the variation of result variable of behavior with $73.30 \%$ at whole group and between $50.10-85.10 \%$ in sub-groups. The causal latent variables of behavior had 6 variables, the order of influent values were family with 0.68 , ability with 0.23 , school with 0.20 , affection with 0.14 , friend with 0.07 and teacher with 0.03 respectively.

Key Words : Causal Relationship Model / Learning Behavior via Internet / Lower Secondary Student / LISREL Program

\section{Introduction}

Act of National Education B.E. 2542 gave meaning of education and defined the meaning of educational management, educational guideline, and learner right that education means learning process for growth and development of person and society by transferring knowledge, training, cultural inheritance, creation for academic progress, creation body of knowledge from environment, learning society and factors to support person to continuously learn as lifelong education. The aim of educational management must be implemented in order to develop Thai people to perfect in all aspects of physical, mind, intelligence, knowledge, and moral with ethics and culture of living. Moreover, they are able to live with others happily. Process of educational management must promote learner to develop as naturally and full competency and let the educational institute to manage learning in every time and every place with cooperation with parents, guardian, and people in community to collaborate to develop the learner along with their competencies including to develop person both technological producer and user for education to have knowledge, capability, and skill in production together with using appropriate technology with quality and efficiency. The leaner had right to develop the competency in technological use for education at first opportunity that he should be received in order to have adequate knowledge and skill to use technology for education to search knowledge by himself continuously as lifelong (Office of National Education Commission, 2002).

From important content of mentioned above Act of National Education, learning of learner had no limitation of time and place while they were only in classroom or educational institute but the learner had a chance to learn all the time and place. The learner will succeed by himself for continuous lifelong learning with his full competency and is congruent to their interesting more or less; it depends on various supporting factors. These included themselves and arrangement of learning experiences from school together with the support from family and society and effective learning media since at 
present age, there is technological progress of computer, information of technology and communication. Particularly, technology of internet is technology that connect the people together all over the world, therefore the computer equipment and internet are electronic equipments that play very important roles as learning media that assist the learner to enter the worldwide of learning conveniently and quickly. As a result of learning via internet network is a way to assist and increase the chance for learner to learn by himself at all time and place with lifelong continuously to serve the aim of National education Act.

However, even though, the electronic equipment is an essential factor for learning process via internet but the learning behavior of student via internet is also an importance to lead to learning results as well; the learner should have appropriate learning behavior that assist to reach the desired learning results.

Bangkok Metropolis is capital of Thailand; there is readiness of electronic equipment and internet network mostly of country and it is a large city that composes with highly educational area with 3 areas but presently, there is no one know that students in different areas was appropriate learning behavior or not and it results from what variables. The researcher is interested to study and develop causal relationship model of learning behavior via internet of lower secondary school students in Bangkok Metropolis by paying attention to causal variables of behavior both external and internal of student (Punthumnavin, 2005) and selected causal relationship model with Structural Equation Model (SEM) and analyzed with LISREL program. The obtained research results would be information to express to causal relationship structure of causal variables toward learning behavior via internet of students and it will be able to use for planning for learning behavior development via internet of student to be appropriate to cause desirable learning results and to be tool for using in lifelong learning continuously.

\section{Research Objectives}

2.1 To study the learning behavior via internet of lower secondary school student in Bangkok Metropolis as whole and classify according to sex and educational area.

2.2 To develop causal relationship model of learning behavior via internet of lower secondary school student in Bangkok Metropolis as whole and classify according to sex and educational area.

\section{Research Hypothesis}

The developed causal relationship model of learning behavior via internet of lower secondary school student had validity.

\section{Research Conceptual Framework}

The dependent or result variable of learning behavior via internet of student and the studied independent or causal variables had characteristics of constructed latent variables from observed variables. The latent behavior composed of 3 observed variables and the each of 6 causal latent variables was constructed from 2-4 observed variables. There were 7 latent variables and 20 observed variables that adapted and improved from Leekitchwatana (2010). The detail of each observed variables of each latent variable were as the followings.

4.1 Latent variable of behavior composed of 3 observed variables that were the followings.

4.1.1 Learning from work that teacher assigned to use internet (Beh1).

4.1.2 Use internet for learning support for various subjects (Beh2).

4.1.3 Use internet for informal learning (Beh3).

4.2 Latent variable of ability composed of 3 observed variables that were the followings.

4.2.1 Ability to use internet (Ab1).

4.2.2 Ability to learn by one-self (Ab2).

4.2.3 Ability to select media perceiving (Ab3).

4.3 Latent variable of affection composed of 4 observed variables that were the followings.

4.3.1 Attitude toward learning via internet (Af1).

4.3.2 Future oriented and self control (Af2).

4.3.3 Achievement Motive (Af3).

4.3.4 Habit of love to read (Af4).

4.4 Latent variable of family composed of 2 observed variables that were the followings.

4.4.1 Family readiness (Fa1). 
4.4.2 Family support (Fa2).

4.5 Latent variable of school composed of 3 observed variables that were the followings.

4.5.1 School readiness (Sc1).

4.5.2 School service provider (Sc2).

4.5.3 School support (Sc3).

4. 6 Latent variable of teacher composed of 3 observed variables that were the followings.

4.6.1 Work assignment of teacher (Te1).

4.6.2 Advice giving of teacher (Te2).

4.6.3 Evaluation of teacher (Te3).

4.7 Latent variable of friend composed of 2 observed variables that were the followings.

4.7.1 Characteristics of friend (Fr1).

4.7.2 Interaction with friend (Fr2).

\section{Research Implementation}

This research was used method of descriptive research and use research model of causal relationship model with structural equation model (SEM).

\subsection{Population and Sample Group}

5.1.1 Population was lower secondary students of school under the Office of The Basic Education Commission in Bangkok Metropolis in academic year of 2011.

5.1.2 Group Sample was lower secondary students of school under the Office of The Basic Education Commission in Bangkok Metropolis in academic year of 2011 from 3 areas with 500 students from each area and the totals were 1,500 students obtained from defining sample size of sample group and sampling method was as the following.

1) Defined the sample size of student sample group of each educational area according to Yamane (1967) at confident level with $95 \%$ and error with $5 \%$. The size of population with $\propto$ and sample group was not lesser than 400 students. This size of sample group is congruent to way of sample size definition with not lesser than 20 times of variables numbers (Department of Educational Research, 2000) hereby, there were 20 observed variables, therefore the sample group were 400 students in each area, therefore, the researcher adjusted to 500 students for each area, therefore the sample group of 3 areas were 1,500 students and defined only the students at 3 level of lower secondary school.

2) Sample group was sampling with Multi-stage random sampling (Leekitchwatana, 2011) as the followings.

Stage 1 Sampling with classifying according to educational area, 10 schools were sampling from each educational area, the sample group was 30 schools.

Stage 2 Sampling with classifying according to school and sex, the 50 lower secondary school students at level 3 were sampling from each school in stage 1 with equal number of both sexes, therefore the sample group was 1,500 students as show in table 1.

Table 1 Number of sample of lower secondary school student at level 3 in Bangkok Metropolis classified according to Sex and Educational Area

\begin{tabular}{l|l|l|l}
\hline \multirow{2}{*}{ Educational Area } & \multicolumn{2}{|l|}{ Number of Students } & \multirow{2}{*}{ Total } \\
\cline { 2 - 3 } & Male & Female & \\
\hline Bangkok Metropolis Area 1 & 250 & 250 & 500 \\
\hline Bangkok Metropolis Area 2 & 250 & 250 & 500 \\
\hline Bangkok Metropolis Area 3 & 250 & 250 & 500 \\
\hline Total & 750 & 750 & 1,500 \\
\hline
\end{tabular}




\subsection{Research Tool}

Research tool was questionnaire for student about learning behavior via internet and the involved variables had group of question with 6 rating scales (6,5,4,3,2 and 1 scores). It composed of 128 items to measure 20 observed variables with content validity and structural validity of 7 latent variables. Confirmatory component analysis by using LISREL program 8.72 , it was found that the model is congruent to empirical data with fit indices met the good criteria that were $\chi^{2}$ value with no statistical significance at 0.05 and $p$-value between $0.433-0.914$, RMSEA=0.000 in every model, RMR between < 0.001-0.007, SRMR between 0.001-0.010, GFI=1.000 and AGFI between 0.998-1.000 (good criteria of fit indices hereby were $\chi^{2}$ value with no statistical significance at 0.05 and $p$-value $>0.05$, RMSEA $<0.05$, RMR $<0.05$, SRMR $<$ $0.05, \mathrm{GFI}>0.90$ and $\mathrm{AGFI}>0.05$ ).

Loading weight of component of every observed variable had statistical significance at 0.01 levels. The importances of observed variables were along with standard loading weight of each latent variable as the followings.

1. Latent variable of behavior composed of 3 observed variables as the followings.

1.1 Computer use for learning support for various subjects learning (0.75).

1.2 Computer use for informal learning (0.74).

1.3 Learning from work that teacher assigned to use internet $(0.73)$.

2. Latent variable of ability composed of 3 observed variables that were the followings.

2.1 Ability to use internet $(0.86)$.

2.2 Ability to learn by one-self $(0.65)$.

2.3 Ability to select media perceiving (0.57).

3. Latent variable of affection composed of 4 observed variables that were the followings.

3.1 Future oriented and self control $(0.80)$.

3.2 Achievement Motive (0.77).

3.3 Attitude toward learning via internet $(0.69)$.

3.4 Habit of love to read (0.67).

4. Latent variable of family composed of 2 observed variables that were the followings.

4.1 Family readiness $(0.79)$.

4.2 Family support (0.53).

5. Latent variable of school composed of 3 observed variables that were the followings.

5.1 School service provider (0.91).

5.2 School readiness $(0.72)$.

5.3 School support $(0.41)$.

6. Latent variable of teacher composed of 3 observed variables that were the followings.

6.1 Advice giving of teacher (0.61).

6.2 Work assignment of teacher (0.59).

6.3 Evaluation of teacher $(0.55)$

7. Latent variable of friend composed of 2 observed variables that were the followings.

7.1 Interaction with friend $(0.98)$.

7.2 Characteristics of friend $(0.64)$.

Model of latent variables had construct reliability $(\rho c)$ between $\mathbf{0 . 4 1 - 0 . 8 4}$ as the following details.

$\begin{array}{ll}\text { Latent variables } & \rho \text { c value } \\ \text { Behavior } & 0.53 \\ \text { Ability } & 0.70 \\ \text { Affection } & 0.82 \\ \text { Family } & 0.41 \\ \text { School } & 0.53 \\ \text { Teacher } & 0.84 \\ \text { Friend } & 0.77\end{array}$

\subsection{Data Collection}

Data collection was conducted by using questionnaire to ask the Students at level 3 who was sample group at school in academic year of 30 schools and 50 students from each school. The questionnaires were returned back 1,500 students 
as defined and it was $100 \%$ classified according sexes that each group were 750 students and classified according to each educational area with 500 students in each group.

\subsection{Data Analysis}

1) Analysis of learning behavior via internet of student as whole and sub-group classified according to sex and educational area with mean $(\overline{\mathrm{X}}$ ) and standard deviation (S) with program SPSS for Windows and interpretation the meaning of mean by using the following criteria.

$\begin{array}{ll}\text { Range of mean } & \text { Behavioral level } \\ 5.50-6.00 & \text { most appropriate } \\ 4.50-5.49 & \text { more appropriate } \\ 3.50-4.49 & \text { moderate appropriate } \\ 2.50-3.49 & \text { less appropriate } \\ 1.50-2.49 & \text { least appropriate } \\ 1.00-1.49 & \text { not appropriate }\end{array}$

2) Analysis of validity of causal relationship model of learning behavior via internet of student and influencing values among variables in model with influencing analysis with latent variables with LISREL program 8.72 both whole and sub-group classified according to sex and educational area by good criteria of fit indices that selected from Viruchchai (1995) and Ungsuchote et.al. (2008) as followings.

$2.1 \chi^{2}$ statistical significance $(p>0.05)$

2.2 RMSEA $<0.05$

$2.3 \mathrm{RMR}<0.05$

2.4 SRMR $<0.05$

$2.5 \mathrm{AGF}>0.90$

$2.6 \mathrm{AGFI}>0.90$

\section{Research Results}

1) Learning behavior via internet of student at lower secondary school level in Bangkok Metropolis.

1.1) Student at lower secondary school level had learning behavior via internet as whole was at moderate appropriate level in every group both whole and sub-group classified according to sex and educational area as the followings.

1.1.1) Whole group $(\bar{X}=4.44, S=0.60)$

1.1.2) Male group $(\bar{X}=4.40, S=0.62)$

1.1.3) Female group ( $\bar{X}=4.47, S=0.58$ )

1.1.4) Educational area 1 in Bangkok Metropolis group ( $\bar{X}=4.39, S=0.58)$

1.1.5) Educational area 2 in Bangkok Metropolis group ( $\bar{X}=4.49, S=0.61$ )

1.1.6) Educational area 3 in Bangkok Metropolis group ( $\bar{X}=4.43, S=0.62$ )

1.2) Considering behavior of student in each aspect in term of whole group, behavior was at more appropriate level 2 aspects and moderate appropriate level 1 aspect. The sequence of order was from most to least levels as the followings.

1.2.1) Learning from work the teacher assign to use internet aspect $(\bar{X}=4.59, S=0.53)$.

1.2.2) Internet use for informal learning aspect ( $\bar{X}=4.57, S=0.79)$.

1.2.3) Internet use for support to learn various academic subject aspect ( $\bar{X}=4.15, S=0.83)$.

2) Causal relationship model of learning behavior via internet of student at lower secondary school level in Bangkok Metropolis.

2.1) Causal relationship model of learning behavior via internet of student at lower secondary school level in Bangkok Metropolis was developed to be model with good validity since model was congruent to empirical 
data in the good criteria for every fit index both whole group and model of 5 sub-groups. In model of whole group, Chi-quare $\left(\chi^{2}\right)$ had no statistical significant, $p$ value=0.116, RMSEA=0.012, GFI=0.995, AGFI=0.983, $\mathrm{RMR}=0.011$ and $\mathrm{SRMR}=0.017$ and in model of 5 sub-groups, $p$ value between $0.057-0.183$, RMSEA between 0.017-0.024, GFI between 0.983-0.990, AGFI between 0.946-0.974, RMR between 0.018-0.023 and SRMR between 0.028-0.037.

2.2) Causal relationship model of learning behavior via internet of student at lower secondary school level in Bangkok Metropolis, the developed model had high effective since the percentage of prediction at high level of every model because prediction model was over 49 percents $\left(R^{2}>0.49\right)$ that were at the prediction criteria level at high level.

In whole group model of the group of the whole causal variables in model was able to explain the variation of result variable of learning behavior via internet of student with 73.30 percents.

In the 5 sub-group models of the group of the whole causal variables in model was able to explain the variation of result variable of learning behavior via internet of student between 50.10-85.10 percents respectively.

The sub-group model was ordered the value from most to less as the followings. The group of educational area 3 was 85.10 percents, the group of female was 79.30 percents, the group of educational area 1 was 74.30 percents, the group of male was 60.90 percents, and the group of educational area 2 was 50.10 percents.

2.3) The structural model of causal relationship between variables in each model had same characteristics but the influent value and important order of causal variables were different as the following details.

2.3.1) Model of whole group

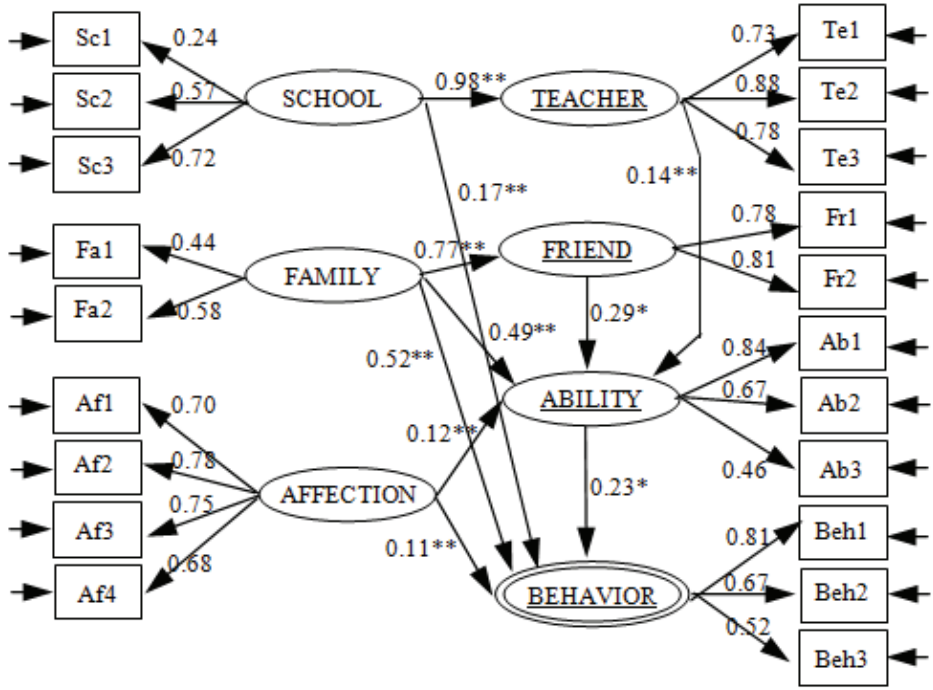

$\chi^{2}=72.172, d f=59, p=0.116$, RMSEA $=0.012$

Figure 1 Diagram of Causal Relationship Model of Learning Behavior via Internet of Lower Secondary Student : whole group

In model of whole group composed of 4 causal variables had positive influent to result variable of learning behavior via internet of student with statistical significance and 2 causal variable had no statistical significance. The 4 variables had statistical significance of influence with order 1-4 to learning behavior, the most was family (0.68) with direct and indirect effects through friend and ability of student. The second order of influent variable was ability $(0.23)$ with direct effect. The third order of influent variable was school $(0.20)$ with direct and indirect effects through teacher and ability of student. The forth order of influent variable was affection (0.14) with direct and indirect effects through ability of student. The other two variables had no statistical significance was fifth order and sixth order. The fifth order was friend (0.07) with indirect effect through ability of student and the sixth was teacher $(0.03)$ with indirect effect through ability of student. 
2.3.2) Model of male group

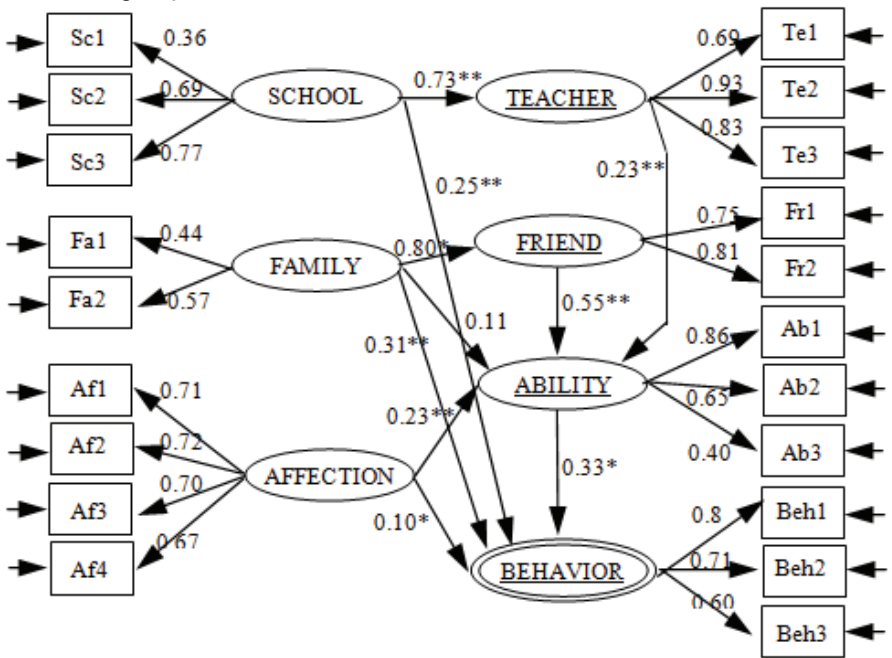

$\chi^{2}=101.583, d f=83, p=0.081$, RMSEA $=0.017$

Figure 2 Diagram of Causal Relationship Model of Learning Behavior via Internet of Lower Secondary Student : male group

In model of male group composed of 6 causal variables had positive influent to result variable of learning behavior via internet of student with statistical significance. The variable had most effect to learning behavior was family (0.49) with direct and indirect through friend and ability of student. The second order variable was ability (0.33) with direct effect. The third order variable was school $(0.30)$ with direct and indirect effects through teacher and ability of student. The forth order was friend $(0.18)$ with indirect effect through ability of student. The fifth order was affection (0.18) with indirect effect through ability of student and the sixth order was teacher $(0.07)$ with indirect effect through ability of student.

2.3.3) Model of female group

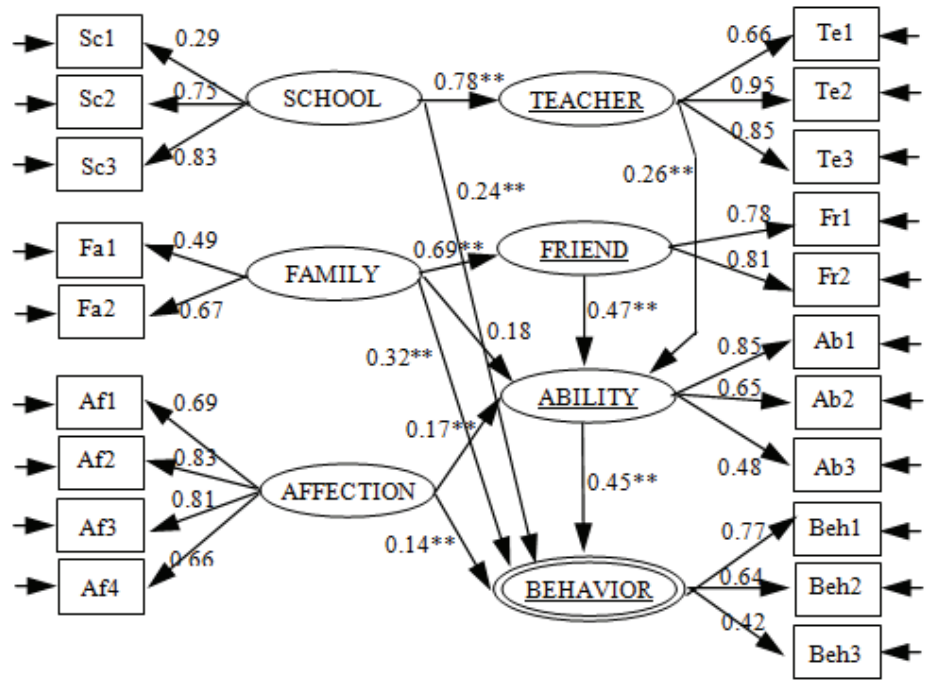

$\chi^{2}=72.442, \mathrm{df}=55, \mathrm{p}=0.058, \mathrm{RMSEA}=0.021$ 
Figure 3 Diagram of Causal Relationship Model of Learning Behavior via Internet of Lower Secondary Student : female group

In model of female group composed of 6 causal variables had positive influent to result variable of learning behavior via internet of student with statistical significance. The variable had most effect to learning behavior was family (0.55) with direct and indirect through friend and ability of student. The second order variable was ability (0.45) with direct effect. The third order variable was school $(0.33)$ with direct and indirect effects through teacher and ability of student. The forth order was affection (0.22) with direct and indirect effects through ability of student. The fifth order friend (0.21) with indirect effect through ability of student and the sixth order was teacher (0.12) with indirect effect through ability of student.

2.3.4) Model of Educational area 1 in Bangkok metropolis group

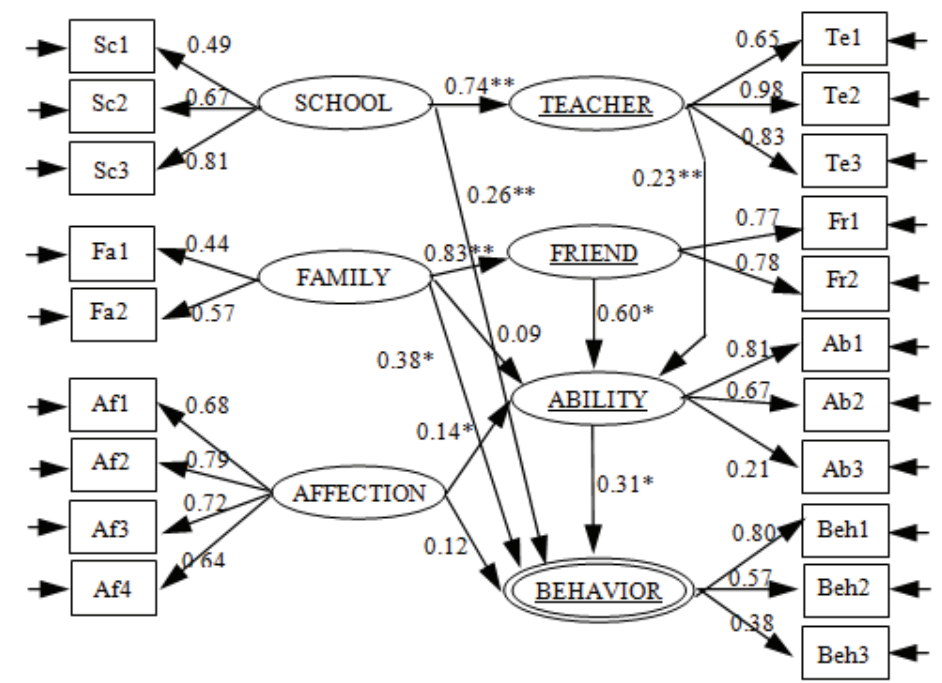

$\chi^{2}=87.074, d f=68, p=0.059$, RMSEA $=0.024$

Figure 4 Diagram of Causal Relationship Model of Learning Behavior via Internet of Lower Secondary Student : Educational area 1 in Bangkok metropolis group

In model of Educational area 1 in Bangkok metropolis group composed of 4 causal variables had positive influent to result variable of learning behavior via internet of student with statistical significance and 2 causal variable had no statistical significance. The 4 variables had statistical significance of influence with order 1-3 and 5 to learning behavior, the most was family $(0.57)$ with direct and indirect effects through friend and ability of student. The second order of influent variable was ability $(0.31)$ with direct effect. The third order of influent variable was school (0.31) with direct and indirect effects through teacher and ability of student. The fifth order of influent variable was affection (0.17) with direct and indirect effects through ability of student. The other two variables had no statistical significance was forth order and sixth order. The forth order was friend $(0.19)$ with indirect effect through ability of student and the sixth was teacher $(0.07)$ with indirect effect through ability of student.

2.3.5) Model of Educational area 2 in Bangkok metropolis group 


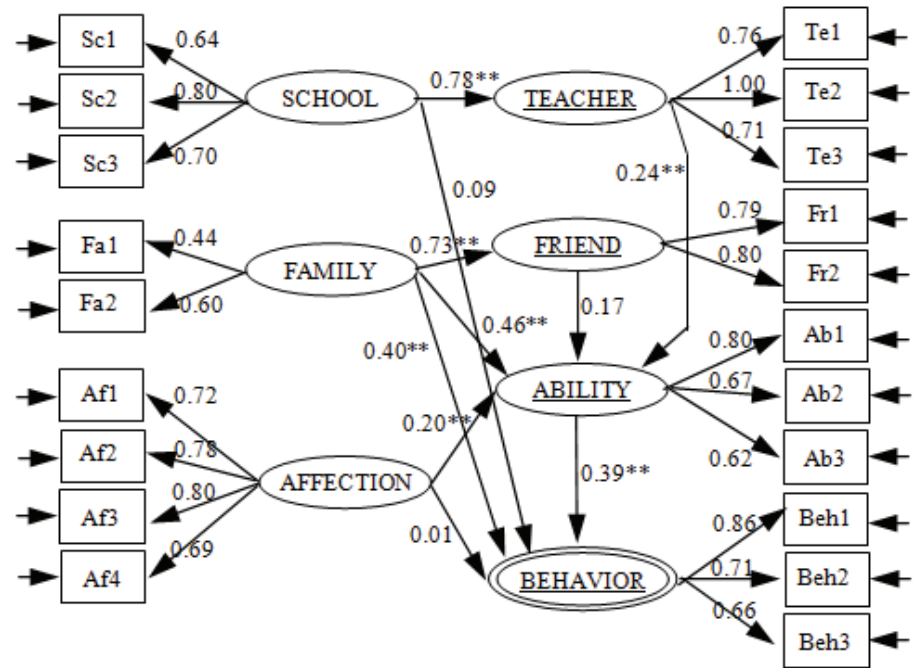

$\chi^{2}=76.399, \mathrm{df}=59, \mathrm{p}=0.063$, RMSEA $=0.024$

Figure 5 Diagram of Causal Relationship Model of Learning Behavior via Internet of Lower Secondary Student : Educational area 2 in Bangkok metropolis group

In model of Educational area 2 in Bangkok metropolis group composed of 4 causal variables had positive influent to result variable of learning behavior via internet of student with statistical significance and 2 causal variable had no statistical significance. The 4 variables had statistical significance of influence with order 1-4 to learning behavior, the most was family $(0.63)$ with direct and indirect effects through friend and ability of student. The second order of influent variable was ability (0.39) with direct effect. The third order of influent variable was school $(0.17)$ with direct effect and indirect effect through teacher and ability of student. The forth order of influent variable was teacher $(0.10)$ with indirect effect through ability of student. The other two variables had no statistical significance was fifth order and sixth order. The fifth order was affection $(0.09)$ with direct and indirect effects through ability of student and the sixth was teacher $(0.07)$ with indirect effect through ability of student.

2.3.6) Model of Educational area 3 in Bangkok metropolis group

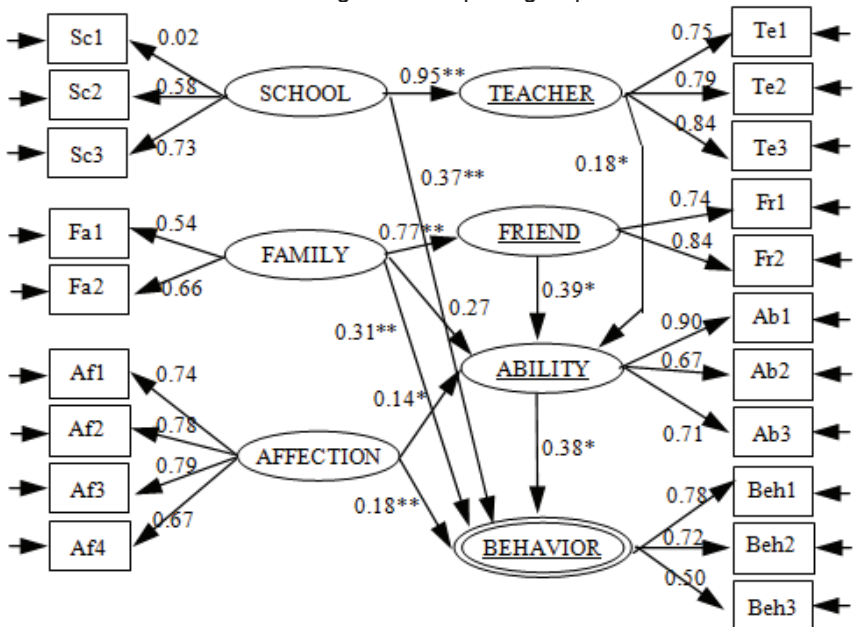

$\chi^{2}=57.783, \mathrm{df}=49, \mathrm{p}=0.183, \mathrm{RMSEA}=0.019$ 
Figure 6 Diagram of Causal Relationship Model of Learning Behavior via Internet of Lower Secondary Student : Educational area 3 in Bangkok metropolis group

In model of Educational area 3 in Bangkok metropolis group composed of 5 causal variables had positive influent to result variable of learning behavior via internet of student with statistical significance and 1 causal variable had no statistical significance. The 5 variables had statistical significance of influence with order 1-4 and 6 to learning behavior, the most was family (0.53) with direct and indirect effects through friend and ability of student. The second order of influent variable was school (0.43) with direct and indirect effects through teacher and ability of student. The third order of influent variable was ability $(0.38)$ with direct effect. The forth order of influent variable was affection (0.23) with direct and indirect effect through ability of student. The sixth order variable was teacher $(0.07)$ with indirect effect through ability of student and another variable had no statistical significant was the fifth was friend $(0.15)$ with indirect effect through ability of student.

2.4) Importance of each causal variable had the closed order in each model, particular family variable was the first important order variable in every model, for the other variables had the same important order of 3-5 models from 6 models. The detail of the importance of each causal variable in each model was ordered according to most to less of influence. The conclusion presented in table 2 .

Table 2 Conclusion Total Effect and Order of Important Order of Total Effect of Causal Variable in Each Model

\begin{tabular}{|c|c|c|c|c|c|c|c|c|c|c|c|c|}
\hline \multirow{3}{*}{$\begin{array}{l}\text { Causal variable } \\
\text { Student Group }\end{array}$} & \multicolumn{4}{|c|}{ Psychological Variable } & \multicolumn{8}{|c|}{ Situational Variable } \\
\hline & \multicolumn{2}{|c|}{ Ability } & \multicolumn{2}{|c|}{ Affection } & \multicolumn{2}{|c|}{ Family } & \multicolumn{2}{|c|}{ School } & \multicolumn{2}{|c|}{ Teacher } & \multicolumn{2}{|c|}{ Friend } \\
\hline & $\begin{array}{l}\text { Total } \\
\text { effect }\end{array}$ & Order & $\begin{array}{l}\text { Total } \\
\text { effect }\end{array}$ & Order & $\begin{array}{l}\text { Total } \\
\text { effect }\end{array}$ & Order & $\begin{array}{l}\text { Total } \\
\text { effect }\end{array}$ & Order & $\begin{array}{l}\text { Total } \\
\text { effect }\end{array}$ & Order & $\begin{array}{l}\text { Total } \\
\text { effect }\end{array}$ & Order \\
\hline $\begin{array}{l}\text { 1. Whole } \\
R^{2}=0.733\end{array}$ & $0.23^{* *}$ & 2 & $0.14^{*}$ & 4 & $0.68^{* *}$ & 1 & $0.20^{* *}$ & 3 & 0.03 & 6 & 0.07 & 5 \\
\hline $\begin{array}{l}\text { 2. Male } \\
\mathrm{R}^{2}=0.609\end{array}$ & $0.33^{* *}$ & 2 & $0.18^{* *}$ & 5 & $0.49^{* *}$ & 1 & $0.30^{* *}$ & 3 & $0.07^{*_{*}}$ & 6 & $0.18^{*}$ & 4 \\
\hline $\begin{array}{l}\text { 3. Female } \\
R^{2}=0.793\end{array}$ & $0.45^{* *}$ & 2 & $0.22^{* *}$ & 4 & $0.55^{* *}$ & 1 & $0.33^{* *}$ & 3 & $0.12^{*}$ & 6 & $0.21^{*}$ & 5 \\
\hline $\begin{array}{l}\text { 4. BBK Area } 1 \\
R^{2}=0.743\end{array}$ & $0.31^{*}$ & 2 & $0.11^{*}$ & 5 & $0.57^{* *}$ & 1 & $0.31^{* *}$ & 3 & 0.07 & 6 & 0.19 & 4 \\
\hline $\begin{aligned} \text { 5. BBK Area } 2 \\
\mathrm{R}^{2}=0.501\end{aligned}$ & $0.39^{*}$ & 2 & 0.09 & 5 & $0.63^{* *}$ & 1 & $0.17^{* *}$ & 3 & $0.10^{*}$ & 4 & 0.07 & 6 \\
\hline $\begin{array}{l}\text { 6. BBK Area } 3 \\
\mathrm{R}^{2}=0.851\end{array}$ & $0.38^{* *}$ & 3 & $0.23^{* *}$ & 4 & $0.53^{* * *}$ & 1 & $0.43^{* *}$ & 2 & $0.07^{*}$ & 6 & 0.15 & 5 \\
\hline
\end{tabular}

${ }^{*} p<0.05,{ }^{* *} p<0.01$

From table 1, it was found that causal variable had the first important order was family with the latent variable that had the most effect to learning behavior via internet of student in every model. Subsequences were ability, school, affection, friend and teacher. Detail of the importance of each casual variable was as the following.

2.4.1) Family variable was the first important order of causal variable with latent variable that had the most effect in every model of both whole group model $(0.68)$ and 5 sub-group models $(0.49-0.63)$. The sub-group was ordered according to the total effect from most to less as the following. Model of group of Bangkok Metropolis Area $1(0.57)$, model of female group (0.55), model of group of Bangkok Metropolis Area $3(0.53)$ and model of male group (0.49) were ordered respectively.

2.4.2) Ability variable was the second important order of causal variable with latent variable that had the second effect in 5 models that were the whole group model (0.23) and 4 sub-group models $(0.31-0.45)$. The sub-group was ordered according to the total effect from most to less as the following. Model of female group (0.45), model of group of Bangkok Metropolis Area 2 (0.39), model of male group (0.33), and model of group of Bangkok Metropolis Area 1 (0.31) and the third order in the sub-group was model of group of Bangkok Metropolis Area 3 (0.38).

2.4.3) School variable the third important order of causal variable with latent variable that had the third effect in 5 models that were the whole group model $(0.20)$ and 4 sub-group models $(0.17-0.33)$. The sub-group was ordered according to the total effect from most to less as the following. Model of female group (0.33), model of 
group of Bangkok Metropolis Area 1 (0.31), model of male group (0.30), and model of group of Bangkok Metropolis Area $2(0.17)$ and the second order in the sub-group was model of group of Bangkok Metropolis Area $3(0.43)$.

2.4.4) Affection variable the forth important order of causal variable with latent variable that had the forth effect in 3 models that were the whole group model $(0.14)$ and 2 sub-group models $(0.22-0.23)$. The sub-group was ordered according to the total effect from most to less as the following. Model of group of Bangkok Metropolis Area $3(0.23)$, model of female group (0.22) and had effect as fifth order in 3 sub-group model $(0.09-0.18)$. The sub-group was ordered according to the total effect from most to less as the following. Model of male group (0.18) model of group of Bangkok Metropolis Area 1 (0.11) and model of group of Bangkok Metropolis Area 2 (0.09).

2.4.5) Friend variable the fifth important order of causal variable with latent variable that had the fifth effect in 3 models that were the whole group model $(0.07)$ and 2 sub-group models $(0.15-0.21)$. The sub-group was ordered according to the total effect from most to less as the following. Model of female group (0.21) and the model of group of Bangkok Metropolis Area $3(0.15)$ and had the forth order effect in 2 sub-group model (0.180.19). The sub-group was ordered according to the total effect from most to less as the following. Model of group of Bangkok Metropolis Area 1 (0.19) and model of male group (0.18) was the sixth order in 1 sub-group model was model of group of Bangkok Metropolis Area 2 (0.07).

2.4.6) Teacher variable was the sixth important order of causal variable with latent variable that had the sixth order effect in 5 models that were the whole group model $(0.03)$ and 4 sub-group models $(0.07-0.12)$. The subgroup was ordered according to the total effect from most to less as the following. Model of female group (0.12), model of male group (0.07), model of group of Bangkok Metropolis Area $1(0.07)$, model of group of Bangkok Metropolis Area $3(0.07)$, and had forth order effect in 1 sub-group model was the model of group of Bangkok Metropolis Area 2 (0.10).

\section{Discussion}

1. This research found that student at lower secondary school student in Bangkok Metropolis had learning behavior via internet as whole at moderate level both in whole group and every sub-group that were male group, female group, group of Bangkok Metropolis Area 1, 2 and 3. There was no risk group that had behavior at less level. The finding of learning behavior at moderate level was congruent to research result of Mathuros (2003) was revealed that upper secondary school student in Pung-Nga Province who participated in the project of computer network for school (SchoolNet Thailand) will use benefit from internet for learning at moderate level. This is congruent to the research of Chantaranipa (2002) that revealed that most of upper secondary school students used internet at moderate level. There was no risk group that had behavior at less level, it might be cause of the limitation of area scope of data only Bangkok Metropolis since this area was society rather readiness in various aspects whether in term of school, teacher, family and student, therefore the result of research illustrated that learning behavior via internet was as a whole at moderate level to most level. However, if data were collected from other sources with limitation of various readinesses, it might be found the risk group of learning behavior at less level, therefore they might need the aid for support more than this.

Considering to the learning behavior in each aspect in whole group, it was found that the behavior had most level more than 2 aspects and moderate level for 1 aspect. The first aspect as the first order was learning from work assigned by teacher to use internet. Subsequence was to use internet for informal learning. Another behavioral aspect as at moderate level was to use internet for supporting to learn different subjects. It was obviously seen that there was a good trend of student to use internet appropriately both for learning according to work assigned by teacher and learning in accordance with their interest or demand of themselves. For learning behavior in aspect of use internet to support for learning different subjects was still at moderate level, therefore their behavior should be developed to be more appropriate. Moreover, if they are paid attentions to improve their readiness, service providing, and more support from school and teaching with the more appropriate quality model, it might be assist them to have more appropriate behavior in this aspect.

2. The finding showed that the developed causal relationship model of learning behavior via internet of lower secondary school student in Bangkok Metropolis had good validity and high effective in every model both whole group and 5 subgroup models.

Group of causal variables in model were able to explain the variation of result variable of learning behavior of student with whole group model with 73.30 percents and explain the variation of sub-group model with $50.10-85.10$ 
percents and it was able to explain most in the model of group of Bangkok Metropolis Area 3 (85.10\%). Subsequences were model of female group (79.30\%), group of Bangkok Metropolis Area $1(74.30 \%)$, whole group model $(73.30 \%)$, and model of male (60.90\%), and explain less in the model of group of Bangkok Metropolis Area $2(50.10 \%)$. The research result of whole group was found that group of casual variables were able to explain the variation of result of learning behavior of student with 73.30 percents. This is congruent to the research result of Leekitchwatana (2010) studied on causal relationship model of learning behavior via electronic media of student at upper secondary school level across the country and it was found that model of middle region that data collection was conducted in Bangkok Metropolis, the group of causal variables were able to explain the variation of result variable of learning behavior of student with 72.40 percents.

In each model composed of 6 causal latent variables of learning behavior via internet of student. The important order of total effect was ordered from most to less in model of whole group was family $(0.68)$, ability $(0.23)$, school $(0.20)$, affection (0.14), friend (0.07) and teacher (0.03). It illustrated that learning behavior via internet of lower secondary school student was effected from different variables both of psychological trait variable that is inside the student in terms of ability and affection, and situational variable that is outside the student in terms of family, school, friend and teacher were effected from situational variable more than psychological trait, therefore it reflected that even through students had psychological trait comprising knowledge, ability and affection that support for learning via internet but they still need the support and promote from society whether family, school, friend, and teacher that are situation as well, therefore it would effect to student to appropriate have learning behavior via internet.

From data analysis, it was revealed that family variable was the first important order, therefore if Thai society is able to develop family institute or parents or guardian to have knowledge and understanding of learning via internet and they participate in support and promote learning of student properly and thoroughly increased. It might be expected that student should have learning behavior via internet more properly; therefore it will be the utilization of electronic media resources to be useful for education and to be more worth for investment of electronic media. Moreover, they would have skill of learning and achieve high learning result for student and would raise the quality of student in another way. Result also showed that the importance of family is congruent Act of National Education B.E. 2542 that defined the educational institute must collaborate with parents and guardian to develop learner according to competency (Office of National Education Commission, 2002). It is obviously seen that parents and guardian to participate for promote and support children in aspect learning via internet at certain level. Even though the effect value just rather high when compare with other variables but it will be good fundamental of collaboration to develop our children in the future.

However, School or institute variable was the third important order in whole model but it is still importance for development of learning behavior via internet of student not lesser than family institute. Even though, effect value of school variable was lesser than family variable but if effect of teacher and friend that important components of school were introduced to consider. The effect value of educational institute might be similar or higher than such as model of male group, model of female group, model of group of Bangkok Metropolis Area 3. The whole group, group of Bangkok Metropolis Area 1 and group of Bangkok Metropolis Area 2 were influenced from family as main but they received influence from school and teach not much. Therefore, it is a good opportunity of school and teacher to improve their role to develop learning behavior via internet of student to be higher level in these 3 groups.

Ability variable was the second effect variable in both whole group model and almost every sub-group models, except the group of Bangkok Metropolis Area 3, that the ability was the third important order but it had total effect $(0.38)$ that linked to the second order in 5 model $(0.23-0.45)$. This is a good sign to reflect that student rather depended on his ability to learn by himself at a certain level, therefore it will be an important characteristics for studying further at higher level that are upper secondary school level and university level. This is a trend of learning by himself via internet increasingly and it will be benefit for daily living and working in the future as well. The finding showed the importance of ability of student that it is congruent to concept of Guglieimino and Guglieimino (2003) mentioned that the readiness of learner via internet had 2 characters that are readiness of technique and readiness of learning with self-direction. Moreover, the ability variable of student would play very important role in terms of variable that effect to learning behavior in the primary order as direct effect and was variable received effect from other causal variable in every model. The importance of causal variable order from most to less in the whole model were family $(0.71)$, friend $(0.29)$, teacher $(0.14)$, school (0.14), and affection (0.12) respectively. If other causal variables in model are developed to be more appropriate, therefore it should be affected to ability and learning behavior of student.

The causal variable that effect to learning behavior of student was revealed in this research is congruent to the research result of Leekitchwatana (2012) that studied on the causal relationship model of learning behavior via electronic of upper secondary school student across the country and revealed that 6 causal latent variable of behavior can be order according to total effect as following. Family (0.46), ability (0.22), school (0.22), affection (0.15), friend (0.13), and teacher $(0.08)$ had important order that is congruent to this research result and had total effect closed to each other with total 
effect of family was found in model of upper secondary school student in this research equaled to 0.68 more than total effect of in model of upper secondary school student with 0.46 . It might be due to lower secondary school student had lesser maturity because they have just passed from child age and are young teenager; therefore they need to get support closely from family. For the upper secondary school student had more maturity because they are older teenager that enter to adult age further and they developed ability for self-dependent and lesser dependent to parents and guardian so the family had lesser effect. This is congruent to the mention of Knowles (1975) that at child age, he is dependent to others, and they need parent or guardian to protect and nurture them. While they grew up and more develop and gradually develop himself to be independent from others. Development is in terms of increment on self-dependent, and self-introduction.

Additionally, some causal variable of behavior is congruent to research result Piset (2005) who studied on causal relationship model of variable that effect to learning with happy of lower secondary school student at level 2 were teacher, learning and teaching management, student characteristics, friend characteristics, and parents and guardian characteristics respectively but only order of variables were different and school variable was another causal variable that is a very important variable in model and causal relationship with latent variable but model Piset had no school variable and causal relationship behavior had no latent variable.

\section{Recommendation}

\subsection{Recommendation from this research}

The research result reflected that learning behavior via internet of student deepened on different variables from both of psychological trait which is internal variable and situational variable which is external variable. Therefore, learning design via internet should regard to both psychological trait and situation of student at least 6 variables that are family, ability, school, affection, friend and teacher to assist student to have appropriate learning behavior that lead to desirable learning result and be a tool for living and learning continuously for lifelong education further. It is a challenge for ability and collaboration of person and involved work unit to develop these important variables to be more proper to effect to have appropriate learning behavior of student. Hereby, the researcher would like to recommend as the followings.

1. Work unit that school is under control should promote and support school to be readiness in terms of physic such as computer laboratory room and internet network system with high speed and readiness of personnel who are teacher and administrator.

2. School should establish projects and activities for learning by using internet of student and promote and develop teacher to be able to arrange learning and teaching by using internet appropriately and thoroughly including providing service with motivation for student to use internet. Moreover, it should communicate with guardian to realize the importance of family to take care and support about internet use of student in order to collaborate for developing the learning behavior to be more appropriate.

However, if any locality or community had limitation of readiness and family support, school should support student with specialty to increase an opportunity for student to use. It might conduct via arrange projects or activities to motivate student to use internet both in terms of each subject according to curriculum and develop other activities for student.

3. Teacher should approve teaching quality by assign work that is able to learn by using internet appropriately for student and giving suggestion about the sources of data and mean of work including evaluating student's work with justice and give feedback to student. Teacher should arrange learning experience via internet in terms of opportunity providing for student and friend to have an interaction in the promotion way of learning each other such as collaborative learning. Moreover, it should create and promote the affection of student that provide to learning via internet such as attitude toward learning via internet, affection of reading, locus of control and future oriented and achievement motive variables which support the student to bring his ability to create advantage for learning.

4. Family should pay attention to take care and support student to be readiness in terms of computer and internet network and internet use for learning and creating affection of student to provide for learning via internet.

5. Student should pay attention for self-development to have knowledge and ability to learn by himself for internet use and be able to select media receiving including crating the relationship with friend to promote learning each other. Student who has high ability and/or family readiness should aid friend who has lesser change to use internet for learning increasingly. 
6. Local work unit should arrange projects/activities for utilization of computer and internet for learning by using benefit from learning center of community ICT that is project in the responsibility of Ministry of Information Technology and Communication with cooperation of provincial administration organization and Sub-district administration organization because at present there is curriculum for parents. If it is distributed widely and emphasized objective for using to support children to use computer and internet for learning increasingly, this will assist the children to be human resources who are able to use information technology as base to be able to gain benefit from internet for learning to develop themselves, community, and nation to strongly sustain in global society.

7. Other work unit in society both of governmental and private sectors should support school to arrange and prepare the physical readiness by providing computer and internet network system with high speed including developing teacher to have knowledge and skill for learning teaching management by using internet with high quality. Additionally, arrangement of projects/activities should be implemented to promote internet use for student, particularly, in local or community with limitation for readiness and/or family.

\subsection{Recommendation for Further researches}

1. It should study on learning behavior via internet and develop causal relationship model of learning behavior via internet of student in other levels, undergraduate, and graduate student and classifying sub-group according to other appropriate variables such as size of school, location of school in city and rural area, work unity control of school etc. Therefore, these will increase body of knowledge to be more complete and might be found the risk group who had learning behavior in inappropriate direction. In order to search mean to develop behaviors of other group should be conducted.

2. It should study on other causal variables added to this model in order to be able to corporately explain the variation of dependent variable increasingly. Example of variable that might be introduced are variable about student background such as age, grade point average, grade in computer subject/information technology including school background, community and family.

3. It should study the model of relationship between causal variable and result variable of learning behavior via internet of student in other method of data analysis such as Hierarchical Linear Model, Hierarchical Multiple Regression, and Analysis of Variance etc. In order to understand this phenomenon in different aspects must be done.

4. It should develop learning media via internet to stimulate and motivate student to use internet for learning increasingly.

5. It should develop model for developing guardian to have knowledge and awareness to realize the importance of learning via internet and to be able to take care and support learning of student to be more appropriate and thoroughly.

6. It should collect and synthesize the way of good practice of school to provide for development of learning behavior via internet of student to distribute for other schools to use this way to be able to reach good practice for developing of learning behavior via internet of student.

\section{References}

Punthumnavin, D. (2005). Behavioral Research for Development of Person and Society" In Document for Workshop Titled Utilization and Production of Research Work for Psychological Behavior for Benefit of Thai Society. Bangkok: Master Research Project. National Research Council of Thailand (NRCT).

Viruchchai, N. (1995). Linear Structural Relationship (LISREL). Second Edition. Bangkok: Faculty of Education, Chulalongkorn University.

Chantaranipa, P. (2002). "Behavior of Internet Use of Upper Secondary: A Case Study of Secondary School in Muang District, Chonburi Province." Master Degree of Political Science. Program General Administratuion, Graduate School. Burapha University.

Leekitchwatana, P. (2010). Research Method in Education. Seventh Edition. Revised version. Bangkok: Faculty of Industrial Education, King Mongkut's Institute of Technology Ladkrabang.

Piset P. (2005). "Causal Relationship Model of Factor Affecting to Learning with Happiness of Lower Secondary School Student Level 2. Journal of Research and Educational Measurement. 4 (1): 95-111.

Department of Educational Research. (2000). "60 years 60 questions of Dr. Nongluck Virachchai" In To be a Teacher Like as Nongluck Virachchai. Bangkok: Faculty of Education, Chulalongkorn University. 
Ungsuchote, S., et.al. (2008). Statistics for Social Science and Behavioral Science: Technique to Use LISREL Program. Bangkok : Mission Media Com. Ltd.

Mathuros, S. (2003). "Factor Influencing to Benefit Use from Internet for Learning Upper Secondary School Student Pung Nga Province In School that Participate the Project of Computer Network for School (SchoolNet Thailand)." Thesis of Master of Education. Program Adult Education. Graduate School. Silapakorn Univertsity.

Office of National Education Commission. (2002). Act of National Education B.E. 2542 and Revised (Copy 2). Bangkok: Priminister Office.

Guglielmino, P.J., and Guglielmino, L.M. 2003. Are Your Learners Ready for E-learning. New York : AMACOM.

Knowles, S. 1975. Self-Directed Learning : A guide for Learners and Teachers. Chicago : Chicago Association Press.

Leekitchwatana, P. (2010). "Development of Causal Relationship Model for e-Learning Behavior of High School Students in Thailand."In E-Learn 2010 Proceedings Volume 4. pp.1944-1952. Edited by Jaime S. and Ke Z. Available : http ://www.aace.org.

Yamane, Taro. 1967. Statistics : An Introduction Analysis. 2nd ed. New York : Harper and Row. 
